\title{
AS POLÍTICAS PÚBLICAS FRENTE À VIOLENCIA SEXUAL CONTRA A MULHER
}

COSTA, Eldessandra Santos ${ }^{1}$

SILVA, Kamila Levino da ${ }^{2}$

Recebido em: 2019.11.15

Aprovado em: 2020.03 .03

ISSUE DOI: $10.3738 / 1982.2278 .3717$

\begin{abstract}
RESUMO: A violência sexual contra a mulher é uma problemática que se entende desde o início da humanidade, no qual, vários órgãos nacionais e internacionais perpassam o tempo em prol de resolvê-la. O objetivo deste trabalho destinou-se a identificar às políticas públicas de saúde direcionadas a atenção à mulher vítima de violência sexual, apresentar os impactos psicológicos da violência sexual na mulher e descrever a atuação do psicólogo na equipe de atenção básica da saúde à mulher vítima de violência sexual. Para tanto, recorreu-se a revisão da literatura, método de pesquisa que usufrui da fonte direta para a coleta de dados, e a abordagem qualitativa como instrumento para interpretar o fenômeno abordado e os seus significados. Diante destes instrumentos de pesquisas, foi possível verificar políticas públicas no âmbito jurídico, social e de saúde direcionadas a acolher e oferecer atendimento à mulher vítima de violência sexual, pois, é sabido que a situação de violência sexual desencadeia prejuízos em suas vítimas, sendo-os físicos, sociais e psicológicos, sobre este último, há uma considerada probabilidade do desencadeamento de psicopatologias como, por exemplo, o transtorno de estresse pós-traumático. Em virtude disto, disponibiliza-se por meio da atenção básica de saúde o serviço de psicologia, como meio de remediar os prejuízos psíquicos sucedidos da violência sexual.
\end{abstract}

Palavras-chave: Atenção básica. Adoecimento psíquico. Psicologia. Terapia cognitiva comportamental.

\section{PUBLIC POLICIES IN FRONT OF SEXUAL VIOLENCE AGAINST WOMEN}

SUMMARY: Sexual violence against women is a problem that has been understood since the beginning of humanity, in which several national and international bodies spend their time in order to resolve it. The objective of this work was to identify public health policies aimed at the care of women victims of sexual violence, to present the psychological impacts of sexual violence on women and to describe the role of the psychologist in the primary health care team for women victims of sexual violence. sexual violence. For that, we used the literature review, a research method that uses the direct source for data collection, and the qualitative approach as an instrument to interpret the phenomenon addressed and its meanings. Given these research instruments, it was possible to verify public policies in the legal, social and health fields aimed at welcoming and offering assistance to women victims of sexual violence, since it is known that the situation of sexual violence triggers losses in their victims, being- the physical, social and psychological aspects of the latter are considered to be likely to trigger psychopathologies such as posttraumatic stress disorder. As a result, the psychology service is made available through primary health care as a means of remedying the psychological damage caused by sexual violence.

Keywords: Basic attention. Psychic illness. Psychology. Cognitive behavioral therapy.

\section{INTRODUÇÃO}

O conceito de violência é ambíguo, complexo e implica vários elementos, a sua origem vem do latim, violentia, que significa o ato de violar outro alguém ou a si mesmo (PAVIANI, 2016). Além de ser compreendida como uma questão política, cultural, policial, jurídica e, principalmente, um caso de saúde pública, a violência não é um problema específico da área da saúde, no entanto, muitas vítimas adoecem a partir da sua ocorrência (BRASIL, 2009).

\footnotetext{
${ }^{1}$ Bacharel em Psicologia (UNESC), Especialista em Saúde mental (FAROL) e Neuropsicologia(CIAP), Mestranda em Psicologia pela Universidade Federal de Rondônia e docente pela Faculdade da Amazônia - RO

${ }^{2}$ Bacharel em Psicologia pela Faculdade da Amazônia (FAMA)
} 
A violência se manifesta de várias maneiras, dentre elas, a sexual. Segundo Facuri et al (2013) para a Organização Mundial da Saúde (OMS) violência sexual é todo ato ou tentativa para obter a ação sexual, sejam elas, investidas ou comentários sexuais indesejáveis contra a sexualidade de uma pessoa usando coerção, para tanto, a violência sexual pode ser entendida como um fenômeno universal, no qual não há restrição de sexo, idade, etnia ou classe social; esta ocorre em diferentes contextos e desde os primeiros registros históricos da humanidade.

Embora ocorra entre homens e mulheres, estas últimas são mais suscetíveis a esse tipo de violência, em quaisquer períodos de suas vidas (BRASIL, 2009). De forma geral, a violência contra a mulher é qualquer conduta, ação ou omissão de discriminação, agressão ou coerção, ocasionada pelo fato de a vítima ser mulher, e que cause dano, morte, constrangimento, limitação, sofrimento físico, sexual, moral, psicológico, social, político, econômico ou perda patrimonial (BRASIL, 2009).

Segundo o Ministério da Saúde em 2015 foram registrados 45.460 estupros no Brasil, com uma média de cinco estupros por hora no país, além disso, os registros do Sistema de Informações de Agravo de Notificação do Ministério da Saúde mostram que, em 2014, 89\% das vítimas de estupro eram do sexo feminino e que $70 \%$ dos estupros foram cometidos por parentes, namorados ou amigos/conhecidos da vítima (BRASIL, 2017).

Tendo em vista este contexto apresentado e os múltiplos prejuízos que podem ser desencadeados a partir da ocorrência da violência sexual, para além, do paradoxo de ter como maior índice de vítimas à mulher, a pergunta norteadora deste estudo é quais as políticas públicas de saúde direcionadas a atenção à mulher vítima de violência sexual?

Sobre isto, o estudo tem como objetivo geral identificar as políticas públicas de saúde direcionadas a atenção à mulher vítima de violência sexual, além de apresentar os impactos psicológicos causados e descrever a atuação do psicólogo na equipe de atenção básica da saúde frente a essa situação.

Para o desenvolvimento deste trabalho, foi adotado a revisão bibliográfica, utilizando o levantamento bibliográfico, baseado em artigos e revistas científicas, trabalhos de conclusão de curso, livros e os arquivos da biblioteca Prof. Esp. José A. de Oliveira.

Justifica-se esse tema pela finalidade de fornecer informações sobre as características das mulheres vítimas de violência sexual, por descrever as formas de agressão em si e os atendimentos disponibilizados na rede pública de saúde, em prol de auxiliar na discussão do problema no âmbito dos serviços de saúde e na dimensão social (FACURI et al., 2013). 


\section{VIOLÊNCIA SEXUAL}

Diversos estudos em Antropologia, Sociologia, Psicologia Social e Saúde Pública entendem a violência como um fenômeno socialmente construído. No âmbito dessas teorizações, a violência é tratada como um fenômeno biopsicossocial, mas cujo espaço de desenvolvimento é a vida em sociedade, podendo assumir formas peculiares em contextos sociais específicos. E por isso, a literatura coloca a violência como um fenômeno de grande complexidade, sendo conceituado de diversas maneiras e a partir de distintas perspectivas. (PEREIRA; PEREIRA, 2011).

Neste sentido, o estudo filosófico tem como tarefa problematizar o conceito, reformular as perguntas sobre a violência, a partir de uma visão ampla que envolve aspectos metafísicos, epistemológicos e éticos; quanto à relação entre ética e violência, pode-se observar posições diferentes, pois, alguns as opõem e distinguem completamente os dois campos; enquanto, outros apresentam a violência como uma dimensão ética, afirmando que a violência implica a intenção de praticar o ato violento (PAVIANI, 2016).

As teorias da violência são necessárias para descrever, analisar e interpretar o fenômeno da violência; estas teorias podem ser científicas, filosóficas ou mistas. As teorias científicas são inúmeras e, mesmo dentro de uma única área de conhecimento, podem surgir diferentes teorias, assim, são mencionadas, entre outras, as teorias sociológicas, psicológicas, psicanalíticas, biológicas, jurídicas e feministas (PAVIANI, 2016).

O conceito de violência é tão amplo que dificilmente as classificações abrangem todas as formas, mas apesar disso, a tipologia de violência pode ser útil para visualizar suas modalidades; entre as formas de violência, é possível mencionar a violência provocada e a gratuita, a real e a simbólica, a sistemática e a não sistemática, a objetiva e a subjetiva, a legitimada e a ilegitimada, a durável e a transitória (PAVIANI, 2016).

\footnotetext{
A violência é tudo que age usando a força para ir contra a natureza de algum ser; é todo ato de força contra a espontaneidade, à vontade e a liberdade de alguém; é todo ato de violação de alguém ou de alguma coisa valorizada positivamente por uma sociedade; é todo ato de transgressão contra aquelas coisas e ações que alguém ou uma sociedade definem como justas e como um direito [...] (PAVIANI, 2016, p.19).
}

Teles e Melo (2003) ao definir violência, afirmam que é o constranger, é tolher a liberdade, é incomodar, é impedir a outra pessoa de manifestar seu desejo e sua vontade, sob pena de viver gravemente ameaçada ou até mesmo ser espancada, lesionada ou morta, é um meio de coagir, de submeter o outro ao seu domínio, é uma violação dos direitos essenciais do ser humano. 
Nas relações humanas, a violência manifesta-se através de comportamentos e ações que as pessoas realizam nas interações estabelecidas e nas mais diversas áreas que atuam, estas ações que não preservam a vida e/ou prejudicam o bem estar tanto individual quanto social. Dessa maneira, todo ser humano é potencialmente violento (já que tem a capacidade de emitir comportamentos violentos), mas sua violência latente pode não se manifestar se não houver estímulos suficientes para desencadeá-la (PEREIRA; PEREIRA, 2011).

Á vista disto compreende-se como violência sexual qualquer ação ou conduta em que o agressor tenha controle sobre outro indivíduo, como por exemplo, subordinação da sexualidade, envolvimento ou ato sexual contra a sua vontade, com o objetivo único de saciar o desejo sexual do agressor, além disso, a violência sexual é considerada como uma das formas de violação dos direitos humanos e um problema de saúde pública. (BEZERRA et al., 2017).

A violência sexual volta-se contra a sexualidade de uma pessoa, por meio da coação praticada por qualquer outra pessoa, independentemente de sua relação com a vítima e em qualquer cenário, inclusive em casa, no trabalho e etc. (NUNES; LIMA; MORAIS, 2017).

No caso da mulher, é possível dividir as vítimas de violência sexual em duas subpopulações: uma que envolve agressor conhecido, em que há menor taxa de procura por auxílio e maior número de atos praticados e composta por mulheres mais jovens, enquanto, a outra por mulheres violentadas por desconhecido com faixa etária mais velha, tendo maiores taxas de agressões físicas, de denúncia e de procura por auxílio (FACURI et al., 2013).

\subsection{Violência sexual na mulher}

As características gerais do conceito de violência variam no tempo e no espaço, segundo os padrões culturais de cada grupo ou época, e são ilustradas pelas dificuldades semânticas do conceito. Alguns exemplos são claros, como a realidade social e a histórica do casamento da mulher, em virtude de que, em determinadas sociedades é submetida a algumas imposições, enquanto, que para outras sociedades tais imposições são consideradas inadequadas. (PAVIANI, 2016).

Desde os primeiros registros da humanidade a apontamentos sobre atos de violência contra a mulher como, por exemplo, durante a propagação do cristianismo e no início da igreja católica romana em meados do século IV, especificamente, no período da inquisição católica, no final do século XVII, no qual, foram deixados rastros de milhões de pessoas mortas, torturadas, assassinas e queimadas; os motivos eram amplos, desde condenar quem não praticava o catolicismo, os que acreditavam na ciência e os acusados de bruxaria (SILVEIRA, 2016). 
Neste último motivo, as mulheres foram as que mais sofreram, pois, a transgressão da fé, num mundo teocrático, também era considerada uma agressão política; junte-se a isso, na sociedade da época, a sexualidade que era livre, principalmente entre as massas populares. Assim, a igreja através da inquisição conseguiu um meio de transformar a transgressão sexual em uma agressão a fé e punir as mulheres por tudo isso (SILVEIRA, 2016).

A mulher era punida pelo seu gênero e principalmente pela sua sexualidade, pois, para igreja católica o espírito é superior, e só tem o corpo para dominar, e esse domínio ocorre através do ato sexual e foi pela sexualidade que o primeiro homem (Adão) pecou. A igreja acreditava que as mulheres copulavam com o demônio, senhor do prazer e, por isso, eram as agentes do domínio, ou seja, conseguiam dominar os homens, e uma vez mantido o ato sexual com o demônio (figura feminina), o poder da feiticeira era capazes de desencadear todos os problemas, como por exemplo, impotência masculina, paixões desenfreadas, abortos, etc. (SILVEIRA, 2016).

Com o passar dos anos, o século XX foi decisivo para o reconhecimento de uma gama de direitos humanos, responsável por profundas modificações na conduta dos diversos segmentos sociais em diferentes regiões do planeta. Desde a Declaração Universal de 1948, o sistema patriarcal ocidental passou, gradativamente, nas legislações posteriores, a reconhecer a diversidade biológica, social e cultural dos seres humanos, criando declarações e pactos específicos para as mulheres (PEREIRA; PEREIRA, 2011).

Apesar do avanço na consolidação dos direitos da mulher no mundo, ainda no início do século XXI não se pode dizer que as mulheres conquistaram uma posição de igualdade perante os homens, além disso, a violência física e psicológica contra a mulher continua a fazer parte do cotidiano da vida moderna e neste e em outros setores, ainda há um longo caminho a ser perseguido (PEREIRA; PEREIRA, 2011).

Paradoxalmente, encontra-se ainda uma vasta lista de atos de violência, cometidos contra a mulher e que afetam, de diferentes formas e em diferentes níveis, o seu desenvolvimento, acarretando, por vezes, prejuízos, irreversíveis à sua saúde física e mental (PEREIRA; PEREIRA, 2011).

Nesse sentido, ao observar-se o passado, nota-se que a história das mulheres é marcada pelo estabelecimento de uma cultura patriarcal, juntamente com as práticas sociais em que estas se responsabilizariam, única e exclusivamente, pelo nascimento e criação dos filhos e cuidados do lar, ou seja, as mulheres foram condicionadas a exercerem sua sexualidade em prol da reprodução, enquanto os homens, pelos proventos do lar, com efeito, essa relação de submissão também reproduziu funções religiosas, políticas e sociais (MACHADO; DEZANOSKI, 2014). 
Esse antigo modelo social, que favoreceu a submissão do gênero feminino e que, apesar de toda mudança ocorrida na sociedade, ainda continua presente na atualidade, mesmo que de maneira menos acentuada, favorece a ideia da força física masculina em contraposição à forma como foi interpretada e construída a noção de fragilidade física feminina e sua condição de reprodutora da espécie humana, para tanto, a consequência dessa relação de dominação, tende a ocasionar um desequilíbrio que, eventualmente, gera um conflito e faz surgir à violência contra a mulher (MACHADO; DEZANOSKI, 2014).

Em virtude disto, a violência sexual contra a mulher consiste em qualquer conduta que constranja a mulher a presenciar, manter ou participar de uma relação sexual não desejada, que induza a mulher a comercializar ou utilizar sua sexualidade, que a impeça de utilizar métodos contraceptivos, que a force a se casar, engravidar, abortar ou se prostituir; isso pode acontecer por meio de intimidação, ameaça, coação, suborno ou uso da força ou manipulação (BRASIL, 2017).

Segundo Albuquerque (2016) estudos atuais destacam as manifestações preconceituosas e discriminatórias contra os indivíduos que assumem uma identidade de gênero e orientação sexual adversa aos padrões heteronormativos, ou seja, que não compõem a orientação natural e/ou heterossexual, destacando-se as mulheres lésbicas, bissexuais, travestis e transexuais (LGBT).

\footnotetext{
Sendo assim, qualquer orientação sexual contrária a esses padrões, como a homossexualidade e bissexualidade, por serem contrárias à dita 'naturalidade imposta', não poderiam ser aceitas socialmente. Nesse sentido, a comunidade LGBT, ao fugir do padrão heteronormativo vigente, provoca conflitos ao contrariar um modelo hegemônico e um sistema de valores, condutas e padrões sociais e sexuais, no qual, qualquer manifestação sexual contrária aos padrões heteronormativos pode vir a ser alvo de violência física, sexual e/ou psicológica (Albuquerque, p. 101, 2016).
}

Todavia, é importante ressaltar que a violência sexual atinge de maneira diferenciada as mulheres negras, indígenas, em situação de rua, com deficiência, lésbicas, bissexuais, da zona rural e da floresta (BRASIL, 2017).

\section{O IMPACTO DA VIOLÊNCIA SEXUAL NA MULHER}

De acordo com o Ministério da Saúde a violência contra a mulher é uma das principais formas de violação dos direitos humanos, atingindo o direito à vida, à saúde e à integridade física (BRASIL, 2017). Segundo a Organização das Nações Unidas (ONU) a violência contra a mulher causa enormes sofrimentos, deixa marcas nas famílias, afetando as várias gerações e empobrece as comunidades, pois, impede que as mulheres realizem as suas potencialidades, limita o crescimento econômico e compromete o seu desenvolvimento (BRASIL, 2009). 
A experiência da violência sexual representa uma das principais causas de doenças e mortalidade entre a população feminina jovem, enquanto, que os homicídios predominam no sexo masculino; a violência sexual atinge principalmente mulheres e crianças, ocasionando sequelas físicas, sociais e emocionais que as tornam mais vulneráveis a vários problemas de saúde. Essas mulheres também apresentam riscos significativos para traumas físicos genitais e extragenitais, desfecho letal, gravidez indesejada, disfunções sexuais e infecções sexualmente transmissíveis (DREZETT et al., 2012).

De acordo com Silva, Gava e Dell'aglio (2013) não existe um padrão de sintomas apresentados por vítimas de violência, as alterações ocorrem de forma heterogênea, podendo, inclusive não ocorrer, sendo assim, não é possível estabelecer uma síndrome para definir e englobar os problemas emocionais, cognitivos e sociais relacionados com a experiência do abuso sexual.

A dificuldade em estabelecer relações causais entre a experiência de abuso e o desenvolvimento de algum transtorno de ordem mental podem ser entendidas em razão de que o impacto da violência sexual é mediado por uma série de fatores. Por conseguinte, não necessariamente as vítimas de abuso sexual irão apresentar sintomas ou desenvolver quadros psicopatológicos, dado que, estudos demonstram a existência de vítimas assintomáticas (SILVA; GAVA; DELL'AGLIO, 2013).

Segundo a OMS 35\% das mulheres em todo o mundo são vítimas de violência física e/ou sexual e em sua maior parte produzida por seus parceiros, estes dados demonstram que as mulheres que sofreram violência sexual são 2,3 vezes mais propensas a desenvolver distúrbios relacionados ao álcool e 2,6 vezes a sofrer de depressão ou ansiedade, desse modo, chama a atenção para o fato de que $12 \%$ a $38 \%$ de todos os assassinatos de mulheres sejam cometidos por parceiros íntimos (BRASIL, 2017).

A violência sexual produz consequências traumáticas e indeléveis para quem a sofre; a gravidez e o adoecimento por infecções sexualmente transmissíveis são consequências possíveis do estupro com conjunção carnal e o atendimento imediato (preferencialmente em até 72 horas) diminui a ocorrência dessas consequências por meio da anticoncepção de emergência e da profilaxia de infecções (BRASIL, 2017).

Todavia, segundo o Ministério da Saúde há mulheres que engravidam em decorrência de violência sexual e a interrupção da gravidez está prevista legalmente nessas situações, ou seja, se uma mulher sofrer violência sexual e engravidar em decorrência dessa violência, ela tem direito à interrupção da gravidez. Além desta situação, está autorizada por lei a interrupção da gestação nos casos de gravidez de fetos anencéfalos e risco de vida para a mulher (BRASIL, 2017). 
Os adoecimentos decorrentes da violência são evidenciados pelo aumento da busca pelos serviços de saúde após a vivência da violência, tanto para o tratamento dos ferimentos atuais quanto para o tratamento das doenças posteriores à violência (BRASIL, 2009).

\subsection{Aspectos psicológicos}

A violência contra a mulher extrapolou os limites jurídicos e estendeu-se para o território da saúde, sobretudo da saúde mental (SILVA; VAGOSTELLO, 2017). Pois, dentre os prejuízos desencadeados pela violência sexual encontram-se o surgimento de algumas psicopatologias como, por exemplo, a depressão, ansiedade, disfunção sexual, desordens da alimentação, risco de suicídio, as alterações no sono e comportamentos, abuso de álcool e drogas e, principalmente, o transtorno de estresse pós-traumático (HATZENBERGE, 2010).

Para tanto, o surgimento de ansiedades sob a forma de medo, vergonha e culpa são comuns em vítimas de violência sexual; nos primeiros momentos, a ansiedade da mulher relaciona-se à sua integridade física, ou seja, ao medo de perder a vida, de contrair infecções sexualmente transmissíveis, sobretudo HIV, e de engravidar e; nos períodos subsequentes, também é comum o medo permanente de ficar só, de sair de casa ou de reencontrar o agressor (SILVA; VAGOSTELLO, 2017).

Outras reações imediatas como tristeza, pesadelos e insônia, sentimentos de humilhação e de solidão, são comuns nos períodos iniciais; muitas mulheres sentem-se sujas e procuram realizar vários hábitos de higienização na tentativa de se livrarem da sensação de sujeira e dos “vestígios” do agressor (SILVA; VAGOSTELLO, 2017).

Para médio e longo prazo, destacam-se os efeitos como depressão e nervosismo crônicos, falta de prazer nas relações sexuais, distúrbios psicossomáticos, isolamento social, dificuldade nos relacionamentos familiares, sentimento de insegurança e medo constante de ocorrer um novo abuso (SILVA; VAGOSTELLO, 2017).

Contudo, mesmo considerando os reflexos fortemente negativos da violência sexual, nota-se que parte considerável dos estudos epidemiológicos desenvolvidos na área da saúde sobre violência sexual permanece no nível descritivo, deixando de aprofundar a discussão e ignorando as outras formas de impacto dessa violência, que afetam a autoestima e a capacidade de reação e decisão das pessoas agredidas (MARTINS, 2011).

\subsection{Transtorno De Estresse Pós-Traumático}

O transtorno de estresse pós-traumático (TEPT) é caracterizado pela presença de memórias intrusivas após a vivência de um evento traumático, ao qual, é acompanhada por 
sintomas de excitação, esquiva de estímulos associados ao trauma e alterações negativas na cognição e no humor (REIS; CARVALHO, 2016).

O quadro possui como característica essencial, o desenvolvimento de uma sintomatologia específica após a exposição a um agente estressor que seja traumático, que pode se desenvolver após uma experiência pessoal direta a um evento real ou ameaçador que resulte em risco de morte, ferimentos ou qualquer ameaça à integridade física do indivíduo ou de outra pessoa (REIS; CARVALHO, 2016).

O TEPT está fortemente associado à exposição a diferentes tipos de violência, como por exemplo, em alguns estudos realizados pela Associação Médica Americana (AMA), foram mensuradas a intensidade e a severidade de eventos estressores a partir do desencadeamento de respostas dissociativas na personalidade, tendo como os primeiros lugares ocupados situações que envolvessem abusos sexuais e abusos físicos intensos e recorrentes (CAMINHA; KRISTENSEN; DORNELLES, 2008).

Em um estudo com 369 mulheres vítimas de violência sexual, verificaram que $40 \%$ das mulheres da amostra desenvolveram TEPT, e que 24\% apresentaram sintomas moderados a severos do transtorno, para tanto, essas mulheres são mais propensas a apresentar maior prevalência do transtorno, bem como têm maior risco condicional para desenvolver o TEPT após exposição em outros eventos estressores (HATZENBERGE, 2010).

\section{POLÍTICAS PÚBLICAS PARA A MULHER VÍTIMA DE VIOLÊNCIA SEXUAL}

Segundo a ONU uma em cada cinco mulheres será vítima ou sofrerá a tentativa de violência sexual em todo mundo; a violência sexual contra as mulheres é vista como uma questão de saúde pública no mundo, demandando o estabelecimento de políticas públicas eficazes. Mulheres com idades entre 15 e 44 anos correm mais risco de serem estupradas e espancadas do que de sofrer de câncer ou acidentes de carro (PINTO et al., 2016).

Nas últimas décadas, em resposta a pressões de movimentos feministas e da própria sociedade, os governos têm implementado políticas públicas e ações de prevenção de violência contra a mulher, sendo elas, para criar e aprimorar normas, bem como expandir serviços com o objetivo de assistir as vítimas; tratando-se das normas, de uma forma geral, sabe-se que a eficácia das leis pode abranger o âmbito jurídico e social; jurídico, quando está apta a produzir efeitos, considerando-se sua vigência e; social, quando efetivamente produz efeitos, sendo aplicada a casos concretos (PINTO et al., 2016).

Segundo Bezerra et al (2017) nas últimas décadas, a questão da violência vem sendo debatida e tendo conquistado visibilidade em campos multidisciplinares, o que viabilizou a 
formulação de políticas e programas de saúde voltados para o enfrentamento. Em virtude disto, ficou sobre responsabilidade das políticas públicas em saúde, integrar o campo de ação social do Estado orientado para a melhoria das condições de saúde da população e dos diversos ambientes sociais; tendo como tarefa básica gerar a promoção, proteção e recuperação da saúde dos indivíduos e da coletividade (LUCCHESE et al., 2004).

As políticas públicas são ações, programas e atividades desenvolvidas pelo Estado para garantir determinado direito de cidadania, é importante destacar que a saúde é um direito social, no qual, isto significa que é de responsabilidade do Estado identificar quais as necessidades da população e criar mecanismos para que isso seja amenizado ou resolvido (SOUZA; SANTANA; ROSA, 2016).

As políticas são constituídas por instrumentos de planejamento, execução, monitoramento e avaliação, são estabelecidas as diretrizes, prioridades e objetivos gerais a serem alcançados a longo prazo; a partir de determinado tema são traçados os objetivos gerais e específicos e as ações para alcançar esses objetivos, regularmente, é necessário avaliar se os objetivos foram alcançados ou se é necessário uma mudança de ação. Por isso é importante conhecermos as políticas que norteiam as nossas praticas profissionais (SOUZA; SANTANA; ROSA, 2016).

Para regulamentar o Sistema Único de Saúde (SUS), foi criada a Lei n. 8.080/90, conhecida como Lei Orgânica da Saúde, que apresenta o objetivo dos SUS, a forma como os serviços devem se organizar e, principalmente, quais os princípios fundamentais e diretrizes que vão guiar os serviços de Saúde (SOUZA; SANTANA; ROSA, 2016).

Desta forma, atualmente quando pensamos nas políticas públicas de saúde, a primeira coisa que nos vem à mente é o SUS, dado que, é a política que orienta a atenção básica de saúde no Brasil; a implantação do SUS pode ser considerada uma das reformas sociais mais significativas realizadas no Brasil; é importante destacar que não era apenas uma mudança no modelo, mas a incorporação de um conceito de saúde ampliado, mais do que apenas ser considerado ausência de doença, em virtude disto, a política de saúde no Brasil passa a adotar o modelo biopsicossocial de saúde (SOUZA; SANTANA; ROSA, 2016).

No Brasil, a legislação que visa assegurar os direitos constitucionais à mulher tem se estabelecido e aprimorado ao longo dos anos, ressalte-se nesse processo a clara tentativa de garantir-se a assistência à vitima de violência, em especial, no tocante ao atendimento de saúde, entretanto, uma lacuna com relação à avaliação da eficácia dos referidos dispositivos legais (PINTO et al., 2016).

No Brasil, até meados do século $\mathrm{XX}$, os homicídios cometidos por parceiros, normalmente tendo como vítimas as mulheres, eram justificados como sendo em legítima defesa 
da honra; o progresso no tema foi incipientemente delineado em 1984, quando o país ratificou o Tratado Internacional da Convenção sobre a Eliminação de Todas as Formas de Discriminação contra a Mulher (PINTO et al., 2016).

Ainda na década de 1990, importantes acordos internacionais, como a Conferência de Cairo (1994), Convenção de Belém do Pará (1994) e Conferência de Beijing (1995), ratificaram a posição do Brasil em relação a violência sexual, entendendo-a como violação aos direitos humanos e como questão de saúde pública (PINTO et al., 2016).

Em 1999, o Ministério da Saúde publicou a edição da Norma Técnica de Prevenção e Tratamento dos Agravos Resultantes da Violência Sexual contra Mulheres e Adolescentes, contendo recomendações gerais de atendimento e apoio psicossocial e protocolos de procedimentos profiláticos; as segunda e terceira edições da referida Norma Técnica vieram a ser publicadas em 2005 e 2012, respectivamente (PINTO et al., 2016).

Em 2003, criou-se a Secretaria de Politicas para as Mulheres, fortalecendo-se as políticas públicas de enfrentamento à violência contra as mulheres por meio da elaboração de conceitos, diretrizes, normas e da definição de ações e estratégias de gestão e monitoramento relativas ao tema; a partir de então, estimulou-se a criação de normas e padrões de atendimento, aperfeiçoamento da legislação, incentivo à constituição de redes de serviços, o apoio a projetos educativos e culturais de prevenção à violência e ampliação do acesso das mulheres à justiça e aos serviços de segurança pública (PINTO et al., 2016).

No Brasil, em 1999 foi instituído o Programa Nacional de Humanização da Assistência Hospitalar (PNHAH) que teve como justificativa: agregar a eficiência técnica e científica a uma postura ética que respeitasse a singularidade das necessidades do usuário e do profissional, aceitando os limites de cada um e a convivência com o desconhecido e o imprevisível (BARBOSA et al., 2013).

Posteriormente ainda sobre os reflexos da PNHAH, em 2003 o Ministério da Saúde implanta a Política Nacional de Humanização (PNH), que tem como princípios teóricos metodológicos: a transversalidade, a inseparabilidade entre atenção e gestão e o protagonismo dos sujeitos e coletivos, ampliando, assim o campo da assistência hospitalar para todos os serviços de atenção a saúde (BARBOSA et al., 2013).

Segundo o Ministério da Saúde a PNH busca reforçar os princípios norteadores do SUS no cotidiano dos serviços de saúde, produzindo mudanças nos modos de gerir e cuidar. Vinculada à Secretaria de Atenção à Saúde do Ministério da Saúde, a PNH conta com equipes regionais de apoiadores que se articulam às secretarias estaduais e municipais de saúde, a partir desta articulação se constroem planos de ação para promover e disseminar inovações nos modos de fazer saúde (BRASIL, 2013c). 
Humanizar se traduz, então, como inclusão das diferenças nos processos de gestão e de cuidado. Tais mudanças são construídas não por uma pessoa ou grupo isolado, mas de forma coletiva e compartilhada, incluir para estimular a produção de novos modos de cuidar e novas formas de organizar o trabalho (BRASIL 2013c, p.03).

Além disso, a humanização se configura como uma aposta ética, estética e política; ética, pois implica que usuários, gestores e trabalhadores estejam comprometidos com a melhoria do cuidado; estética porque permite um processo criativo e sensível da produção da saúde por sujeitos autônomos e protagonistas de um processo coletivo; política refere-se à organização social e institucional, onde se espera que haja solidariedade dos vínculos estabelecidos, dos direitos dos usuários e da participação coletiva do processo de gestão (BARBOSA et al., 2013).

A Política Nacional de Humanização atua a partir de orientações clínicas, éticas e políticas, que se traduzem em determinados arranjos de trabalho (BRASIL, 2013c). Todavia, para a construção de uma nova forma de cuidado com os usuários dos serviços de saúde pautados na humanização, leva-se em consideração que o usuário deva ter uma abordagem integral e humana, para tanto, devem ser respeitados os seus saberes que são ligados a sua cultura e que dão sustentação a sua forma de perceber seu processo de adoecimento (BARBOSA et al., 2013).

Esta Política de Humanização também traz como desafio a ser superado, a fragmentação existente nas atividades programáticas, quais sejam: a humanização da assistência hospitalar, do parto, do nascimento, do morrer, entre outros; cabe aos profissionais romper com a lógica presente na assistência, marcada pela prática de atender apenas a queixas, passando a traçar possibilidades de efetivo encontro entre trabalhador-usuário e trabalhador-trabalhador, em que as pessoas não sejam vistas como um diagnóstico de doença, para tanto, é preciso que os encontros sejam marcados pela singularidade e pela subjetividade dos sujeitos envolvidos ( BARBOSA et al., 2013).

Além disso, de acordo com o Ministério da Saúde o acolhimento é um conceito frequentemente utilizado para expressar as relações que se estabelecem entre usuário e profissionais na atenção à saúde, no entanto, não se trata de uma simples relação de prestação de serviço, mais do que isso, o acolhimento implica uma relação cidadã, humanizada e de escuta qualificada (BRASIL, 2010).

O acolhimento expressa uma ação de aproximação, de relação com o usuário que procura os serviços de saúde, a qual, não se restringe apenas ao ato de receber, mas se constitui em uma sequência de atos e modos que compõem as metodologias dos processos de trabalho em saúde em qualquer nível de atenção, para isso, preconiza-se que a humanização permeie o encontro entre os trabalhadores e usuários, a partir de uma relação de escuta e responsabilização, na qual o paciente é portador e criador de direitos (PROCHNOW et al., 2009). 
Em 2011, definiu-se a Política Nacional de Enfrentamento à Violência contra as Mulheres cuja finalidade é estabelecer conceitos, princípios, diretrizes e ações de prevenção e combate à violência contra as mulheres, assim como de assistência e garantia de direitos aquelas em situação de violência, conforme normas e instrumentos internacionais de direitos humanos e legislação nacional (PINTO et al., 2016).

Publicada em 01 de agosto de 2013, a Lei 12.845 dispôs sobre o atendimento obrigatório e integral de pessoas em situação de violência sexual, de forma que todos os hospitais integrantes da rede do SUS devem oferecer às vítimas de violência sexual atendimento emergencial, integral e multidisciplinar, visando ao controle e ao tratamento dos agravos físicos e psíquicos decorrentes de violência sexual (PINTO et al., 2016).

Conforme o Artigo $3^{\circ}$ da Lei $n^{\circ} 12.845$, de 01 de agosto de 2013:

\begin{abstract}
Art. $3^{\circ} \mathrm{O}$ atendimento imediato, obrigatório em todos os hospitais integrantes da rede do SUS, compreende os seguintes serviços: I - diagnóstico e tratamento das lesões físicas no aparelho genital e nas demais áreas afetadas; II - amparo médico, psicológico e social imediatos; III - facilitação do registro da ocorrência e encaminhamento ao órgão de medicina legal e às delegacias especializadas com informações que possam ser úteis à identificação do agressor e à comprovação da violência sexual; IV - profilaxia da gravidez; V - profilaxia das Doenças Sexualmente Transmissíveis - DST; VI - coleta de material para realização do exame de HIV para posterior acompanhamento e terapia; VII - fornecimento de informações às vítimas sobre os direitos legais e sobre todos os serviços sanitários disponíveis" (BRASIL, 2013b, p. 01).
\end{abstract}

Além disso, o decreto $\mathrm{N}^{\mathrm{o}} 7.958 / 2013$ estabelece diretrizes para $\mathrm{o}$ atendimento às vítimas de violência sexual pelos profissionais de segurança pública e da rede de atendimento do Sistema Único de Saúde, tais como: atendimento humanizado, levando em consideração os princípios do respeito da dignidade da pessoa, da não discriminação, do sigilo e da privacidade, disponibilização de espaço de escuta qualificado e privacidade durante o atendimento, para propiciar ambiente de confiança e respeito à vítima, disponibilização de transporte à vítima de violência sexual até os serviços de referência; promoção de capacitação de profissionais de segurança pública e da rede de atendimento do SUS para atender vítimas de violência sexual de forma humanizada; assistência farmacêutica e de outros (BRASIL, 2013a).

De acordo com o Ministério da Saúde uma das principais ferramentas no enfrentamento à violência contra a mulher é a Vigilância de Violências, instrumentalizada pelo setor Saúde no Sistema VIVA (Sistema de Vigilância de Violências e Acidentes - VIVA). Um dos instrumentos da vigilância é a notificação compulsória dos casos de violência contra mulheres atendidas nos serviços de saúde públicos ou privados. Os dados da notificação são restritos ao Setor Saúde (BRASIL, 2017).

A notificação de violências para a autoridade sanitária é uma exigência da lei, fruto de uma luta contínua para que a violência contra estes segmentos da população saia da 
invisibilidade, revelando sua gravidade, o perfil das pessoas envolvidas e outras características destes eventos (BRASIL, 2017).

Além disso, a notificação de violência contra as mulheres, meninas e adolescentes é importante para: compreender a situação da violência contra as mulheres nos municípios, estados e no país, revelando os casos que permanecem ocultos nos espaços privados e públicos e subsidiando as políticas públicas para a atenção, prevenção de violências, promoção da saúde e da cultura da paz; intervir nos cuidados em saúde, promovendo atenção integral às mulheres em situação de violência e a garantia de direitos por meio da rede de atendimento à mulher (BRASIL, 2017).

\section{ATUAÇÃo DO PSICÓlOGO NA ATENÇÃo BÁSICA À MULHER VÍTIMA DE VIOLÊNCIA}

A sexualidade tem relevância legitimada pela Organização Mundial de Saúde, que a reconhece como um dos pilares da qualidade de vida, portanto, é garantido ao ser humano o direito à saúde sexual, que é definida como um estado de bem-estar físico, emocional, mental e social relacionado à sexualidade (LARA, 2009).

O conceito de sexualidade é bem abrangente, podendo ser entendido como um aspecto da vida humana que inclui as sensações corpóreas e as questões emocionais, que diz respeito a várias manifestações e não somente a sexo, pois, quando pensamos em sexo, nos referimos às práticas sexuais, no qual, são comportamentos que envolvem os órgãos genitais (MAIA, 2014).

Todo ser humano vive e cresce desenvolvendo sua sexualidade a partir das mudanças ocorridas ao longo do desenvolvimento, o que inclui o crescimento e amadurecimento do corpo físico, as práticas sexuais e reprodutivas, a orientação sexual e o erotismo, os vínculos amorosos e entre outros. Sendo assim, o ser humano é capaz de sentir bem-estar diante de sensações prazerosas táteis, sensações confortantes diante da afetividade, vindo de relacionamentos conjugais, fraternos ou de amizade (MAIA, 2014).

Todavia, o trauma sucedido da violência sexual é entendido pelo uso distorcido da sexualidade. A literatura destaca que só será possível a ressignificação da situação traumática a partir da revelação que a vítima faz, no qual, essa revelação abrirá possibilidades de inserção na rede de atendimento que vai possibilitar o trabalho terapêutico tão necessário (ARPINI; SIQUEIRA; SAVEGNAGO, 2012).

Eventualmente, as mulheres vítimas de violência sexual apresentam dificuldades de realizarem denúncia, principalmente em decorrência do medo e da suspeita de falta de veracidade 
do fato, dado que, evidencia-se uma clara dificuldade de serem escutadas pelos familiares e a comunidade em si (ARPINI; SIQUEIRA; SAVEGNAGO, 2012).

Fazendo-se necessário à construção de uma comunicação livre, um espaço de discussão nos ambientes sociais e familiares, no qual, os obstáculos relacionados ao diálogo sobre sexualidade possam ser diminuídos e as dificuldades superadas (ARPINI; SIQUEIRA; SAVEGNAGO, 2012).

A rede de enfrentamento a violência sexual, em especial os Centros de Atendimento Especializados em Vítimas de Violência é uma importante política pública que integra a rede de Atenção Básica (AB), este serviço tem como objetivo trabalhar as consequências da violência sexual, promover a ressignificação do trauma (a partir da experiência psicoterapêutica) para a reorganizando da sexualidade (ARPINI; SIQUEIRA; SAVEGNAGO, 2012).

Desde a Constituição Federal de 1988 e a implantação do SUS, no campo da saúde houve mudanças da concepção clássica de atenção à saúde, que atualmente se sustenta em um conceito ampliado de saúde, tendo como um de seus objetivos principais a reorientação do modelo assistencial a partir da Atenção Básica entendida como condições de vida que atua no nível primário de atenção através da Estratégia de Saúde da Família (ESF) (ALEXANDRE; ROMAGNOLI, 2017).

Compreender o processo de constituição da ESF a partir da criação do Núcleo de Apoio à Saúde da Família (NASF) é fundamental para entender como o profissional de psicologia vem se integrando ao SUS, especificamente à $\mathrm{AB}$, para tanto, o psicólogo não é membro efetivo das Equipes de Saúde da Família (EqSF) mas se articula com as mesmas equipes por meio do NASF, criado como forma de aumentar o acesso e a qualidade da AB (ALEXANDRE; ROMAGNOLI, 2017). .

Esse processo de inserção da psicologia nas políticas públicas e, especialmente, no campo da saúde na ESF proporcionou ao psicólogo outras práticas clínicas para além do consultório e de uma prática que não privilegiasse apenas a lógica secundária e terciária da clínica tradicional, no qual, emerge uma dimensão coletiva em outro plano da produção de subjetividade (ALEXANDRE; ROMAGNOLI, 2017).

Segundo o Ministério da Saúde, dentre os atendimentos disponibilizados a vítima de violência sexual na $\mathrm{AB}$, destaca-se o atendimento psicológico, no qual, o psicólogo poderá atuar a partir da avaliação psicológica e a psicoterapia de grupo. (BRASIL, 2009).

De acordo com o Conselho Federal de Psicologia (CFP, 2019) a avaliação psicológica atua nos diversos campos de aplicação da psicológica, como na psicologia da saúde e na hospitalar, com a finalidade de avaliar os fenômenos psicológicos de ordem cognitiva, comportamental, social e afetiva em diferentes contextos, a partir de estudos aprofundados sobre 
fundamentos, métodos e técnicas de obtenção e análise integrativa de informações para avaliação de fenômenos, processos e construtos psicológicos.

Neste sentido, no atendimento à mulher vítima de violência sexual ao psicólogo é relevante identificar os sentimentos predominantes: medo, angústia, tristeza, culpa, revolta etc.; aplicar testes ou utilizar técnicas psicológicas; avaliar o grau de desorganização da vida social e o estado emocional geral no momento; encaminhar para avaliação psiquiátrica, caso necessário e; dentre outros (BRASIL, 2009).

Entende-se por psicoterapia de grupo os resultantes das interações provenientes das experiências humanas e das ações do psicoterapeuta, utilizando-se de fatores psicoterapêuticos como promovedores de mudanças, dentre os quais, destaca-se a universalidade por promover o alívio dos pacientes por perceberem que não estão sozinhos para enfrentar seus problemas; a aprendizagem social pela simples observação de como os outros participantes compreendem, interpretam ou reagem diante dos temas tratados no grupo; socialização: pela simples convivência em grupo e dentre outros (HELDET; et al., 2008).

Sendo assim, no atendimento com as mulheres vítimas de violência sexual, caberá ao profissional facilitar a identificação e expressão de sentimentos decorrentes da situação de violência; trabalhar a autoestima das mulheres; examinar os vários papéis da mulher, sugerir maneiras para melhorá-los e/ou criar novos se necessário; facilitar o relato de experiências comuns; promover o sentimento de solidariedade entre elas e dentre outros (BRASIL, 2009).

Além disso, em caso de gravidez decorrente desta forma de violência ao profissional é relevante trabalhar os sentimentos relacionados à constatação da gravidez fruto da violência sexual (ambivalência, culpa, rejeição, aprovação); identificar e trabalhar as fantasias e mitos quanto à gravidez e ao Aborto Previsto em Lei; acompanhamento psicológico tanto em casos de interrupção da gravidez quanto frente à opção pela gestação e dentre outros (BRASIL, 2009).

Embora haja pouca publicação sobre a atuação da psicologia no contexto de violência sexual contra a mulher, a literatura salienta que a intervenção psicológica deve privilegiar a promoção da resiliência, além disso, o acompanhamento psicoterapêutico, independentemente da abordagem teórica, deve proporcionar um ambiente seguro e de aceitação para que a mulher se sinta acolhida e protegida, bem como aliviar o sofrimento (SILVA; VAGOSTELLO, 2017).

Para tanto, o caráter favorecedor do processo psicoterapêutico com as vítimas de violência sexual esta em trabalhar a reconstrução psíquica, o reestabelecimento de conexões entre funções psíquicas dissociadas, a recuperação de interesses perdidos, como a sexualidade e o desejo de relacionar-se com o outro, além de permitir que novos objetivos e perspectivas sejam estabelecidos (SILVA; VAGOSTELLO, 2017). 


\subsection{A Terapia Cognitiva Comportamental}

Diferentes intervenções têm sido propostas para o atendimento da vítima de violência sexual, a terapia cognitivo-comportamental tem apresentado resultado superior ao de outras abordagens não focais no tratamento da violência sexual; a intervenção cognitivocomportamental (TCC) possui como funcionalidade modificar comportamentos inadequados ou de risco, desenvolver habilidades para prevenir novas situações de violência e melhorar a qualidade vida da paciente (LUCÂNIA, 2009).

Em diversas literaturas a terapia cognitivo-comportamental é destaca pela grande validade em evidências científicas, tanto na área emocional ou mesmo na área médica, pois, esta abordagem permite a mensuração dos seus resultados e, direcionada para realização de metas e resolução de problemas, por usar um método fundamentalmente educativo (LIPP, 2012).

O processo psicoterapêutico de orientação cognitivo-comportamental com vítimas de violência sexual propõe uma intervenção diretiva, estruturada e orientada para a redução dos sintomas agudos, dos níveis de estresse e do sofrimento psíquico, cujo objetivo é o ganho de autonomia e a melhora na qualidade de vida da mulher (SILVA; VAGOSTELLO, 2017).

Para isso, a literatura destaca a importância do processo de reestruturação cognitiva por meio de técnicas de autodiálogo, dessensibilização sistemática, parada de pensamento, desempenho de papéis, respiração profunda para relaxamento, treino em solução de problemas, treino de habilidades sociais, entre outros (SILVA; VAGOSTELLO, 2017).

O manejo psicoterapêutico da TCC compreenda as etapas de avaliação inicial, intervenção, avaliação final e acompanhamento após a alta; a evolução do trabalho e a avaliação de alta devem ser consideradas de acordo com a remissão dos sintomas e com a aquisição de novos repertórios cognitivo-comportamentais (SILVA; VAGOSTELLO, 2017).

Além disso, o trabalho grupal também se revela eficaz no tratamento, uma vez que o grupo favorece a comunicação da própria história e a troca de experiências; a verbalização da vivência traumática e a identificação com outras mulheres auxiliam na progressiva integração de sentimentos, na elaboração e na ressignificação do trauma, permitindo que novos objetivos e perspectivas de vida sejam estabelecidos (SILVA; VAGOSTELLO, 2017). 


\section{METODOLOGIA}

\subsection{Tipo de estudo}

O presente trabalho trata-se de uma revisão de literatura, ou seja, um estudo secundário que tem como fonte de dados estudos primários que relatam resultados de pesquisas em primeira mão (GALVÃO; PEREIRA, 2014). Para tanto, utilizou-se uma investigação científica, como meio de identificar, avaliar e sintetizar as evidências relevantes ao tema, tendo como base a pesquisa bibliográfica, dado que, por seu intermédio é possível obter contato direto com matérias já escritas referentes ao assunto abordado (PRODANOV; FREITAS, 2013).

A utilização deste método de pesquisa pautou-se em fornecer respostas às questões significativas para a compreensão da sua natureza, ao qual, se destinou como básica por gerar novos conhecimentos para o avanço da ciência, sem ocorrer a sua prática (GERHARDT; SILVEIRA, 2009).

Além disso, pelo seu manejo bibliográfico, buscou-se salientar as evidencias do fenômeno estudado, a partir de registros históricos, movimentos e descrições científicas que contemplam e abrangem a violência sexual contra a mulher em suas problemáticas e maneiras de resoluções.

Sendo assim, pelos objetivos apresentados considera-se esta pesquisa também como descritiva, visto que, seu objetivo primordial é a descrição das características de determinada população/fenômeno para o estabelecimento de relações entre suas variáveis e características (GIL, 2002).

Neste sentido, tendo em vista estes métodos que usam a fonte direta para a coleta de dados e que emprega diferentes alegações de conhecimento e estratégias de investigação (CRESWELL, 2007). Recorreu-se a abordagem qualitativa como meio de interpretar o fenômeno estudado e seus significados (PRODANOV; FREITAS, 2013).

6.2 Fonte de dados

Partindo do lócus de pesquisas em Periódicos Eletrônicos de Psicologia (PEPSIC), Scientific Electronic Library Online (SCIELO), Biblioteca Virtual em Saúde (BVS), Portal da Legislação, Portal do Conselho Federal de Psicologia (CFP), o acervo de arquivo da Biblioteca Prof. Esp. José A. de Oliveira em Vilhena/RO e dentre outros.

Deste modo, a partir da análise dos materiais foi possível encontrar conteúdos contendo informações de como as políticas públicas de saúde se posicionam frente a mulher vítima de 
violência sexual; verificou-se as características das mulheres mais vulneráveis a esta forma de violência; para onde elas devem ir após a ocorrência da violência; os serviços que são garantidos por lei e que tem a obrigatoriedade de ocorrer; os meios legais a se buscar em prol de prevenir ou remediar a ocorrência da violência sexual e entre outros.

\section{3 Coleta de dados}

Tendo realizado a identificação e a localização das obras norteadoras da pesquisa, foram selecionados os conteúdos bibliográficos sobre violência sexual contra a mulher, políticas públicas de saúde e a atuação do psicólogo na atenção básica, no período de 2009 a 2019, com exceção para as bibliográficas clássicas referentes ao tema abordado, onde foram excluídos os conteúdos que não correspondiam aos critérios de inclusão citado.

Após este levantamento bibliográfico, foi realizado a pré-seleção dos conteúdos, a partir da leitura dos títulos e resumos, para posteriormente, chegar-se ao embasamento teórico. Efetuouse a leitura para alcançar respostas ao problema proposto, no qual seguiu pelas seguintes etapas: a identificação das informações relevantes ao tema, a leitura dos textos e os dados apresentados pelos autores.

Para tanto, sobre a perspectiva da abordagem qualitativa, na análise dos dados foi utilizado um conjunto de técnicas que visam obter os objetivos de descrição do conteúdo das mensagens, para além de realizar uma reflexão sobre as condições de produção e apreensão do significado de textos produzidos em seus diferentes campos (GERHARDT; SILVEIRA, 2009).

\section{CONSIDERAÇÕES FINAIS}

São inúmeros os impactos desencadeados pela ocorrência da violência e que afetam o ser humano na sua totalidade biopsicossocial, especialmente, ao que se refere à mulher, pois, historicamente são mais suscetíveis a alguns tipos de violência assim como os homens. Ainda sobre elas, vários estudos salientam que a violência sexual volta-se em grande massa à mulher devido, principalmente às questões de gênero.

Em virtude disto, fica sobre responsabilidade das grandes organizações, especificamente do Estado oferece estratégias e planejamentos voltados ao cuidado deste ser/mulher que precisa de uma proteção e um amparo tendo em vista as vulnerabilidades apontadas.

Algumas políticas públicas de saúde estão direcionadas a acolher e oferecer atendimento á vítima de violência sexual, destacando, a rede de atenção básica; as intervenções hospitalares e 
os órgãos médicos legais para a comprovação da violência; os encaminhamentos para os outros âmbitos legais como, as delegacias especializadas, dentre outros.

Se tratando de violência sexual contra mulher, várias são as consequências que comprometem a sua saúde e bem-estar, podendo até se tornar irreversíveis como o surgimento de doenças crônicas, como a AIDS, por exemplo, e de algumas psicopatologias já citadas no texto. Sobre essa última, encontrou-se pouca ênfase nos estudos epidemiológicos do SUS e dentre outros meios sobre as severas consequências geradas pelo adoecimento psíquico posterior ao trauma ordinário à violência sexual.

O episódio traumático ocasionado pela ocorrência da violência sexual, especificamente, quando a vítima tem o seu corpo violado necessitando da intervenção hospitalar, ressalta, nestes casos, a importância do atendimento humanizado, visto que, os prejuízos não são apenas visíveis, mas, há um grande sofrimento psíquico ocasionado por este acontecimento e que precisa ser validado e acolhido em suas particularidades.

Em função disto, independente de quaisquer intervenções da equipe multidisciplinar, o acolhimento humanizado para a vítima de violência sexual é de suma importância, ao fato de que, como em qualquer outra forma de violência, a vítima não optou pela invasão da sua integralidade.

Neste sentido, um dos principais meios de assistência à mulher vítima de violência sexual corresponde ao serviço de psicologia na $\mathrm{AB}$, este serviço ampara tanto as demandas iniciais como as de longo prazo.

Nas demandas iniciais, recomenda-se a avaliação psicológica, por ter, como um dos objetivos, avaliar os sentimentos frente a ocorrência da violência sexual, tais como, medo, raiva, tristeza e outros.

Nas demandas de longo prazo, considera-se mais apropriada a terapia de grupo, pela finalidade de trabalhar a ressignificação com as mulheres vítimas de violência sexual, onde, o profissional poderá utilizar como recurso a aprendizagem social e as intervenções da terapia cognitiva comportamental.

De forma geral, este estudo teve como finalidade fornecer informações de como as políticas públicas se posicionam frente à mulher vítima de violência sexual; para onde ela deve ir após a ocorrência da violência; os serviços que são garantidos por lei e que tem a obrigatoriedade de ocorrer e; os meios legais a se buscar em prol de prevenir ou remediar a sua ocorrência.

Sabe-se que a violência sexual é pauta das políticas nacionais de saúde, no entanto, ainda há altos índices da sua ocorrência, necessitando de mais mobilização de conhecimento e informação sobre esta temática e a divulgação dos programas de assistência como meio de minimizar, prevenir os impactos e proporcionar seguridade e qualidade de vida às mulheres. 
Por esses aspectos a necessidade de estudos na área, é de fundamental importância tanto para o meio acadêmico como social, pois, na medida em que se investiga, surge a possibilidade de se prevenir e/ou intervir sobre o processo que a desencadeia, minimizando suas consequências. A pesquisa pode vir a ser útil também para o Ministério da Saúde, Secretária de saúde do Estado e também futuros pesquisadores do tema.

\section{REFERÊNCIAS}

ALBUQUERQUE, G. A. Violência psicológica em lésbicas, gays, bissexuais, travestis e transexuais no interior do Ceará, Brasil. Rio de Janeiro: Rev. Saúde em Debate v. 40, n. 109, p. 100-111, 2016. Disponível em:< http://www.scielo.br/pdf/sdeb/v40n109/0103-1104-sdeb-40109-00100.pdf>. Acesso em: 02 nov. 2019.

ALEXANDRE, M. DE L; ROMAGNOLI, R. C. Prática do Psicólogo na Atenção Básica SUS: conexões com a clínica no território. São Leopoldo: Contextos Clínicos vol.10, 2017. Disponível em:http://pepsic.bvsalud.org/scielo.php?script=sci_arttext\&pid=S198334822017000200013. Acesso em: 02 nov. 2019.

ARPINI, D. M; SIQUEIRA, A. C; SAVEGNAGO, S. D. O. Trauma psíquico e abuso sexual: o olhar de meninas em situação de vulnerabilidade. Psicol. teor. prat. vol.14 no.2 São Paulo ago. 2012. Disponível em: < http://pepsic.bvsalud.org/scielo.php?script=sci_arttext\&pid=S151636872012000200008>. Acesso em: 22 maio, 2019.

BARBOSA G. C; et al., Política Nacional de Humanização e formação dos profissionais de saúde: revisão integrativa. Brasília: REBEn ed. 66, 2013. Disponível em:

<http://www.scielo.br/pdf/reben/v66n1/v66n1a19.pdf> . Acesso em: 10 set. 2019

BEZERRA, J. F; et al. Assistência à Mulher Frente à Violência Sexual Políticas Públicas de Saúde Revisão Integrativa. Fortaleza: RBPS, 2017. Disponível em: <https://periodicos.unifor.br/RBPS/article/view/6544/pdf>. Acesso em: 29 mar. 2019.

BRASIL. Decreto $\mathbf{n}^{\mathbf{0}} \mathbf{7 . 9 5 8}$ de 13 de março de 2013. Estabelece diretrizes para o atendimento às vítimas de violência sexual pelos profissionais de segurança pública e da rede de atendimento do Sistema Único de Saúde. Brasília: Diário Oficial da União, 2013a. Disponível em:

<http://www.planalto.gov.br/ccivil_03/_ato2011-2014/2013/decreto/d7958.htm>. Acesso em: 26 set. 2019

BRASIL. Lei 12.854, de 1 de agosto de 2013. Dispõe sobre o atendimento obrigatório e integral de pessoas em situação de violência sexual. Brasília: Diário Oficial da União, 2013b. Disponível em:<http://www.planalto.gov.br/ccivil_03/_Ato20112014/2013/Lei/L12845.htm>. Acesso em: 26 set. 2019.

BRASIL. Ministério da Saúde. Acolhimento nas práticas de produção de saúde. Brasília. 2. ed., 2010. Disponível em: <

http://bvsms.saude.gov.br/bvs/publicacoes/acolhimento_praticas_producao_saude.pdf >. Acesso em: 29 mar.2019. 
BRASIL. Ministério da Saúde. PNAISM: Documento de apoio às Conferências de Saúde das Mulheres Municipais, Regionais e Estaduais. Brasília, 2017. Disponível em:

<http://conselho.saude.gov.br/ultimas_noticias/2017/doc/05maio02_2cnsmu_MS.pdf>. Acesso em: 20 ago. 2019.

BRASIL. Secretaria de Atenção à Saúde. Cartilha da PNH: Política Nacional de humanização. Brasília, 2013c. Disponível em:

<http://bvsms.saude.gov.br/bvs/publicacoes/politica_nacional_humanizacao_pnh_folheto.pdf>. Acesso em: 29 mar. 2019.

BRASIL. Secretaria de Estado de Saúde do Distrito Federal. Manual para atendimento às vítimas de violência na rede de saúde pública do DF. Brasília: Cartilha Saúde ed. 2, 2009. Disponível em:

http://bvsms.saude.gov.br/bvs/publicacoes/manual_atendimento_vitimas_violencia_saude_public a_DF.pdf . Acesso em: 19 maio 2019.

CAMINHA, R. M; KRISTENSEN, C. H; DORNELLES, V. G. Terapia cognitivocomportamental no transtorno de estresse pós-traumático. In: CORDIOLI, A.V. (Org.).

Psicoterapias: abordagens atuais. 3. ed. Porto Alegre: Artmed, 2008. Cap. 27. p. 486-509.

CONSELHO FEDERAL DE PSICOLOGIA. Resolução no 18, de 05 de setembro de 2019.

Reconhece a Avaliação Psicológica como especialidade da Psicologia e altera a Resolução CFP $\mathrm{n}^{\mathrm{o}}$ 13, de 14 de setembro de 2007. Disponível em: https://atosoficiais.com.br/cfp/resolucao-doexercicio-profissional-n-18-2019-reconhece-a-avaliacao-psicologica-como-especialidade-dapsicologia-e-altera-a-resolucao-cfp-no-13-de-14-de-setembro-de-2007-que-institui-aconsolidacao-das-resolucoes-relativas-ao-titulo-profissional-de-especialista-empsicologia?origin=instituicao\&q $=$ Avalia\%C3\%A7\%C3\%A3o\%20psicologica. Acesso em: 30 nov. 2019.

CRESWELL, J. W. Projeto de pesquisa: métodos qualitativos, quantitativo e misto. Porto Alegre: Artmed. ed. 2, 2007.

DREZETT, J. A clínica em situações de abuso sexual: aspectos conceituais e atuação interdisciplinar. São Paulo: Rev. O Mundo da Saúde, 2012. Disponível em:

<http://bvsms.saude.gov.br/bvs/artigos/mundo_saude/clinica_situacoes_abuso_sexual_aspectos.p df>. Acesso em: 23 maio 2019.

FACURI, C. de O; et al., Violência sexual: estudo descritivo sobre as vítimas e o atendimento em um serviço universitário de referência no Estado de São Paulo, Brasil. Rio de Janiero: Cad. Saúde Públ., 2013. Disponível em:http://www.scielo.br/pdf/csp/v29n5/08.pdf . Acesso em 19 abr. 2019.

GALVÃO, T. F; PEREIRA, M. G. Revisões sistemáticas da literatura: passos para sua elaboração. Brasília: Epidemiol. Serv. Saúde v.23, 2014. Disponível em: http://scielo.iec.gov.br/scielo.php?script=sci_arttext\&pid=S1679-49742014000100018 . Acesso em: 15 out. 2019.

GERHARDT, T. E; SILVEIRA, D. T. Métodos de pesquisa. Porto Alegre: Editora da UFRGS, 2009. Disponível em: < http://www.ufrgs.br/cursopgdr/downloadsSerie/derad005.pdf> . Acesso em: 10 maio 2019. 
GIL, A. C. Como elaborar projetos de pesquisa. 4 ed. São Paulo: Atlas, 2002.

HATZENBERGE, R; et. al. Transtorno de estresse pós-traumático e prejuízos cognitivos em mulheres vítimas de violência pelo parceiro íntimo. Rio de Janeiro: Ciênc. Cogn. vol.15, 2010. Disponível em:http://pepsic.bvsalud.org/scielo.php?script=sci_arttext\&pid=S180658212010000200009. Acesso em: 30 set. 2019.

HELDT, E. et al. Terapia cognitivo-comportamental em grupo para transtorno de ansiedade. In: Cordioli, A. V. et al (Org.). Psicoterapias: Abordagens Atuais. 3. ed. Porto Alegre: Artmed, 2008. Cap. 18. p. 316-337.

LARA, L. A. S. Sexualidade, saúde sexual e Medicina Sexual: panorama atual. Rio de Janeiro: Rev. Bras. Ginecol. Obstet. vol.31, 2009. Disponível em:< http://www.scielo.br/scielo.php?script=sci_arttext\&pid=S0100-72032009001200001> . Acesso em 07 jan. 2020.

LIPP, M. E. N. Bases Teóricas da Terapia Cognitivo-Comportamental. In: LIPP, M. E. N; YOSHIDA, E. M. P. (Org.). Psicoterapias Breves: nos diferentes estágios evolutivos. São Paulo: Casa do Psicólogo, 2012. Cap. 1. p. 20-36.

LUCÂNIA, E. R; et al., Intervenção cognitivo-comportamental em violência sexual: estudo de caso. Maringá: Psicol. estud. vol.14, 2009. Disponível em: http://www.scielo.br/scielo.php?script=sci_arttext\&pid=S1413-73722009000400022 . Acesso em: 26 set. 2019.

LUCCHESE, P. T. R. et al., Políticas públicas em Saúde Pública. São Paulo: BIREME/OPAS/OMS, 2004. Disponível em: http://files.bvs.br/upload/M/2004/Lucchese_Politicas_publicas.pdf . Acesso em: 22 maio 2019.

MACHADO, I. V; DEZANOSKI, M. Exploração do Conceito de Violência Psicológica na Lei 11.340/06. In: SANTOS, F. L. (Org.). Paraíba: Rev. Gênero e Direito, 2014. Disponível em:https://periodicos.ufpb.br/index.php/ged/article/view/18063/10568 . Acesso em: 29 ago. 2019.

MARTINS, R. C. Abuso sexual e resiliência: enfrentando as adversidades. Fortaleza: Rev. MalEstar Subj. vol.11, 2011. Disponível em: http://pepsic.bvsalud.org/scielo.php?script=sci_arttext\&pid=S1518-61482011000200011 . Acesso em: 02 out. 2019.

NUNES, M. C. A; LIMA, R. F. F; MORAIS, N. A. Violência Sexual contra Mulheres: um Estudo Comparativo entre Vítimas Adolescentes e Adultas. São Paulo: Rev. Psi. Ciência e Profissão. vol. 37, 2017. Disponível em:http://www.scielo.br/pdf/pcp/v37n4/1414-9893-pcp-3704-0956.pdf . Acesso em: 20 maio 2019.

PAVIANI, J. Conceitos e formas de violência. In: MODENA, M. R. (Org.). Conceitos e formas de violência. Caxias do Sul, Rs: Educs, 2016. Cap. 1. p. 8-20.

PEREIRA, M. N. C; PEREIRA, M. Z. C. A violência doméstica contra a mulher. Paraíba: Rev. Espaço do Currículo, vol. 04, 2011. Disponível em: http://www.periodicos.ufpb.br/ojs2/index.php/rec/article/view/10540/5827. Acesso em: 10 set. 2019. 
PINTO, L. S. S; et al. Políticas públicas de proteção à mulher: avaliação do atendimento em saúde de vítimas de violência sexual. Rio de Janeiro: Rev. Ciência e Saúde Coletiva, 2016. Disponível em: https://www.scielosp.org/pdf/csc/2017.v22n5/1501-1508/pt . Acesso em: 30 set. 2019.

PROCHNOW, A. G; et al. Acolhimento no âmbito hospitalar: perspectivas dos acompanhantes de pacientes hospitalizados. Porto Alegre: RGE, 2009. Disponível em: http://www.seer.ufrgs.br/index.php/RevistaGauchadeEnfermagem/article/view/5347/6555. Acesso em: 29 mar. 2019.

PRODANOV, C. C, FREITAS, E. C. Metodologia do trabalho científico: Métodos e Técnicas da Pesquisa e do Trabalho Acadêmico. Novo Hamburgo: Univ. FEEVALE. ed. 2, 2013.

REIS, A. M; CARVALHO, L. F. Produção científica sobre o Transtorno de Estresse Pós-Traumático no contexto de desastres. São Francisco: Rev. Avaliação Psicológica, 2016. Disponível em: http://pepsic.bvsalud.org/pdf/avp/v15n2/v15n2a13.pdf . Acesso em: 30 set. 2019.

SILVA, D. G; GAVA, L. L; DELL'AGLIO, D. D. Sintomas e quadros psicopatológicos em supostas vítimas de abuso sexual: uma visão a partir da psicologia positiva. Canoas: Aletheia ed. 40, 2013. Disponível em: http://pepsic.bvsalud.org/scielo.php?script=sci_arttext\&pid=S141303942013000100006. Acesso em: 25 ago. 2019.

SILVA, E. P; VAGOSTELLO, L. Intervenção psicológica em vítimas de estupro na cidade de São Paulo. Rio de Janeiro: Arquivos Brasileiros de Psicologia, 2017. Disponível em: http://pepsic.bvsalud.org/pdf/arbp/v69n3/13.pdf . Acesso em: 02 out. 2019.

SILVEIRA, S. V. da. A inquisição e a violência contra a mulher. In: MODENA, M. R. (Org.). Conceitos e formas de violência. Caxias do Sul, Rs: Educs, 2016. Cap. 9. p. 110-115.

SOUSA, A. A. F; SANTANA, C. L. A de. As Políticas de Saúde no Brasil. In: ROSA, A. S; SANTANA, C. L. A. de (Org.). Saúde mental das pessoas em situação de rua: conceitos e práticas para profissionais da assistência social. São Paulo: Epidaurus Medic, 2016. Cap. 5. p. 90100.

TELES, Maria Amélia de Almeida; MELO, Mônica. O que é violência contra a mulher. São Paulo: Coleção Primeiros Passos - Brasiliense, 2003. 